\title{
Simulation Studies on Indoor Relative Humidity Maintenance in Rural Residential Buildings Using Sustainable Building Materials
}

\author{
M.Nadarajan ${ }^{1 *}$, Dr.V.Kirubakaran ${ }^{2}$, \\ ${ }^{1}$ Research Scholar, Rural Energy Centre, The Gandhigram Rural Institute -Deemed University, Gandhigram- \\ 624302. Tamilnadu, India. \\ ${ }^{2}$ Assistant Professor, Rural Energy Centre, The Gandhigram Rural Institute-Deemed University, Gandhigram- \\ 624302. Tamilnadu, India.
}

\begin{abstract}
Humidity is an indoor environmental factor that can affect thermal comfort inside a building. Sustainable construction techniques to create and maintain healthy indoor condition, based on ecological principles and through an efficient use of resources are the requirement nowadays. Common cause of moisture during the hot season is excessive indoor humidity, caused by an improper balance between moisture generation and moisture removal. Here two sustainable wall materials mud block and burnt brick with rattrap bond construction used in rural residential sector were considered for indoor relative humidity variation analysis with reference to the heat gain by solar radiation into the building, using CFD simulation technique. It was observed that the relative humidity variations and the heat transfer into the houses depend on the heat gain from the roof and walls and that, the mud block walled houses posses more indoor relative humidity variations than rat trap bond brick walled houses.
\end{abstract}

Keywords: Thermal comfort, relative humidity, CFD analysis, mud block, rat trap bond, sustainable building materials

\section{Introduction}

Indoor thermal comfort is said to be achieved when occupants are able to perform without any hindrance, activities for which the building is intended. The indoor thermal comfort includes three basic parameters air temperature, relative humidity and air velocity. Less observational studies were done on the direct effect of humidity on thermal comfort. Currently, the return backs to investigating the environmental factors such as air movement, humidity and indoor air quality capture more research interests.

Humidity is one among the indoor environmental factors that could affect thermal comfort inside a building. Hot and humid climate will develop a condition of thermal discomfort in a building. A common cause of moisture problems during the hot season is excessive indoor humidity, caused by an improper balance between moisture generation and moisture removal. With the emergence of energy shortages, climatic changes and sick building syndromes, builders have recognized the necessity in finding strategies that can cultivate a more sustainable design for satisfactory indoor thermal comfort. Experimental studies on airborne transmitted infectious bacteria and viruses have shown that the survival or infectivity of these organisms is minimized by exposure to relative humidity between 40 and $70 \%$.

Sustainability in construction techniques has to result in the creation and responsible maintenance of a healthy built environment, based on ecological principles, and through an efficient use of resources. Buildings not only use the existing resources such as energy and raw materials but they also generate the waste and potentially harmful atmospheric emissions and hence the sustainability in construction industry offers an outstanding response to the current environmental and socio economic problems.[1]

In this study two sustainable building materials commonly used in rural building construction sector in southern parts of India, mud block and burnt brick were selected. Two model houses built with mud block walls and rattrap bond brick walls were analyzed using CFD for the variations in the indoor relative humidity due to outdoor solar incident radiation on walls and roof and the results were presented.

\section{Indoor Relative Humidity Maintenance For Comfort}

The primary function of a building is to adapt to the prevailing climate and provide an internal and external environment that is comfortable and conducive to the occupants. However, due to climate changes and global warming, providing comfort for the occupants of a building is quite challenging. Indoor thermal comfort is achieved when occupants are able to perform without any hindrance, activities for which the building is intended. The thermal comfort basically includes three parameters air temperature, relative humidity and air velocity $[2,3]$. ASHRAE 55-1992 set the maximum air relative humidity at $60 \%$. This is because mold and mildew start to grow beyond this limit. At low relative humidity, the increase in evaporation rate may cause skin 
drying and irritation. When humidity and moisture are not effectively controlled persistent dampness can lead to material damage, corrosion, structural decay, and microbial growth, including mold [4,5].

Hot and humid climate will develop a condition of thermal discomfort in a building. Perhaps, air conditioning will be an answer to this problem of uncomfortable condition but the process of air conditioning requires energy which most of the people in the developing countries have limited affordability. [6]

With the emergence of energy shortages, climatic changes and sick building syndromes associated with the common usage of mechanical ventilation systems, authorities have recognized the necessity in finding strategies that can cultivate a more sustainable design in line with satisfactory indoor thermal comfort. Without doubts, natural ventilation can be an appropriate solution for these deteriorating problems. Although the concept of natural ventilation is not complicated, it is a challenge to design naturally ventilated buildings as natural ventilation is difficult to control. We may not have choices for the local climate conditions like solar radiation, humidity, air temperature, wind speed, etc., which are determinative for the feasibility of natural ventilation in certain regions, successful facade designs by architects and engineers, including the thermal property of construction materials, window sizes, shading, and building orientations, and effective ventilation strategies can provide an optimum modifier to achieve better indoor thermal comfort with minimum energy usages. [2]

In recent years, hygrothermal simulation gained importance in building analysis. It is differentiated between building component simulation and whole building simulation. The component simulation, therefore, needs prescribed conditions for interior temperature and relative humidity. Moisture load in the rooms is positive in winter, with a higher interior absolute humidity than outside, and thus dominated by the moisture production in the room. In summer months, due to dehumidification both climate zones show negative moisture loads. [7]. Air dry bulb temperature, mean radiant temperature, air velocity and humidity are the most known environmental parameters in the field of thermal comfort studies. Indoor moisture management, which means keeping the indoor relative humidity at correct levels, is very important for whole building performance in terms of indoor air quality, energy performance and durability of the building. [4,8]

\subsection{Relative humidity maintenance for healthy indoors}

Many reviews on the health effects of relative humidity in indoor environments suggest that relative humidity can affect the incidence of respiratory infections and allergies. Experimental studies on airborne transmitted infectious bacteria and viruses have shown that the survival or infectivity of these organisms is minimized by exposure to relative humidity between 40 and $70 \%$. The incidence of absenteeism or respiratory infections was found to be lower among people working or living in environments with mid range versus low or high relative humidity. The majority of adverse health effects caused by relative humidity would be minimized by maintaining indoor levels between 40 and 70\%. The recommendation from experts on the in home humidity set point is $55 \% \mathrm{RH}$, so that the actual humidity in a home does not exceed $60 \%$. The motivation for this value is largely to minimize mold, mildew, dust mites and other allergens in a home Although water vapor is not typically thought of as an indoor contaminant, multi zone indoor air quality modeling can be used to predict water vapor concentrations in each zone by applying mass balance equations that incorporate water vapor sources and sinks. $[9,3,10]$

\subsection{Relative humidity maintenance in residential buildings}

A common cause of moisture problems during the hot season is excessive indoor humidity, caused by an improper balance between moisture generation and moisture removal. This improper balance can be improved by three methods. One is to reduce the sources of moisture, another is to increase the removal rate by ventilation or dehumidification, and the other is to enhance the level of insulation. In the case of residential buildings, it is more difficult to reduce moisture origins, related to resident's behaviours, than to increase the removal rate. Therefore, it is necessary to control variations in relative humidity by regulating airflow [11].

Even in buildings with high quality insulation excessive indoor humidity conditions may occur because the occupants produce too much moisture which is not compensated by adequate ventilation. Such behaviour may lead to moisture problems like condensation or mould growth on external walls. During the winter months the mean value of indoor relative humidity should be lower than $40 \%$ and during the summer months, the highest values for mean indoor air humidity amount up to approximately $70 \%$. Factors which influence indoor relative humidity are as expressed below.

Neglecting the air exchanges from adjacent rooms the humidity balance within a residential building room can be defined as follows:

$\mathrm{V} \cdot \mathrm{dc}_{\mathrm{i}} / \mathrm{d} \tau=\sum_{\mathrm{j}} \mathrm{A}_{\mathrm{j}} \mathrm{g}_{\mathrm{wj}}+\mathrm{n} . \mathrm{V}\left(\mathrm{c}_{\mathrm{a}}-\mathrm{c}_{\mathrm{i}}\right)+\mathrm{W}_{\mathrm{IFQ}}^{\cdot}+\mathrm{W}_{\mathrm{RLT}}^{\cdot}$

Where,

$\mathrm{V}$ - room volume $\left[\mathrm{m}^{3}\right]$

$\mathrm{A}_{\mathrm{j}}$ - enclosure surfaces $\left[\mathrm{m}^{2}\right]$

$c_{i}-$ absolute humidity of indoor air $\left[\mathrm{kg} / \mathrm{m}^{3}\right]$ 
$\mathrm{c}_{\mathrm{a}}$ - absolute humidity of outdoor air $\left[\mathrm{Kg} / \mathrm{m}^{3}\right]$

$\mathrm{g}_{\mathrm{wj}}$ - humidity exchange between building envelope and indoor air $\left[\mathrm{kg} / \mathrm{m}^{2} \mathrm{~h}\right]$

$\mathrm{n}$ - air exchange (exchange of indoor air by outside air) $[1 / \mathrm{h}]$

$\mathrm{W}_{\mathrm{IFQ}}^{*}$ - indoor humidity generation by internal moisture sources $[\mathrm{kg} / \mathrm{h}]$

$\mathrm{W}_{\mathrm{RLT}}^{*}-$ moisture supply or removal by ventilation and air conditioning systems $[\mathrm{kg} / \mathrm{h}]$

Building component layers at a distance of more than $10 \mathrm{~mm}$ below the surfaces can be neglected, as they are not reached by daily fluctuations of indoor relative humidity and they are only influenced by the mean indoor relative humidity. Therefore, only the daily or monthly mean values of indoor relative humidity are relevant to assess the moisture control performance of building envelope systems. Very high or very low relative humidity and condensation phenomena can compromise building occupant's health and comfort. Controlling humidity and maintaining a comfortable humidity range for occupants is necessary. Generally, most people will be comfortable in a humidity range of $30-80 \%$ if the air temperature is in a range of $18-24^{\circ} \mathrm{C}$.

Since the last decade many theoretical and less experimental work of thermal and moisture behaviour of building has been done. Many researchers were interested in thermal behaviour, others only in moisture behaviour. It was specified that indoor humidity depends on several factors, such as moisture sources, air change, sorption in materials and possible condensation. Since all these phenomena are strongly dependent on each other numerical predictions of indoor humidity need to be integrated into combined heat and airflow simulation tools. $[12,13]$

\section{CFD Analysis On Model Houses Built With Sustainable Building Materials.}

The widely used sustainable building material in India is earth and is a part of its culture. Approximately 55\% of all Indian houses still use raw earth for walls. Traditionally, mud construction varies enormously with topography, climatic condition and needs of different regions.

Another relatively cheap sustainable building material is burnt brick and the construction technique is simple. The brick masonry technique with rattrap bond brick requires less number of bricks than normal construction method and are preferred recently for small to very small rural residential buildings. From an environmental and structural point of view, masonry performance depends on the performance of mortar and brick units, and their composite behaviour.

Hence the two sustainable wall materials mud block and burnt brick with rattrap bond wall construction for residential houses were considered for relative humidity analysis and comparison towards the relative humidity variations with reference to the heat gain by solar radiation into the building, using CFD simulation.

We performed CFD analysis on CAD generated model houses one with mud block walls and another with rat trap bond brick wall. The model houses were meshed with hexahedral mesh type with mesh count 190608, maximum skewness 0.9 and minimum orthogonal quality 1.0. The model houses analyzed with CFD were of size $10 \mathrm{ft} \times 10 \mathrm{ft} \times 10 \mathrm{ft}$, roof and floor were built with cement concrete and the side walls of one built with rat trap bonded bricks and other one with mud blocks. One front door and two window openings in the side walls of standard size were provided as shown in figure 1.
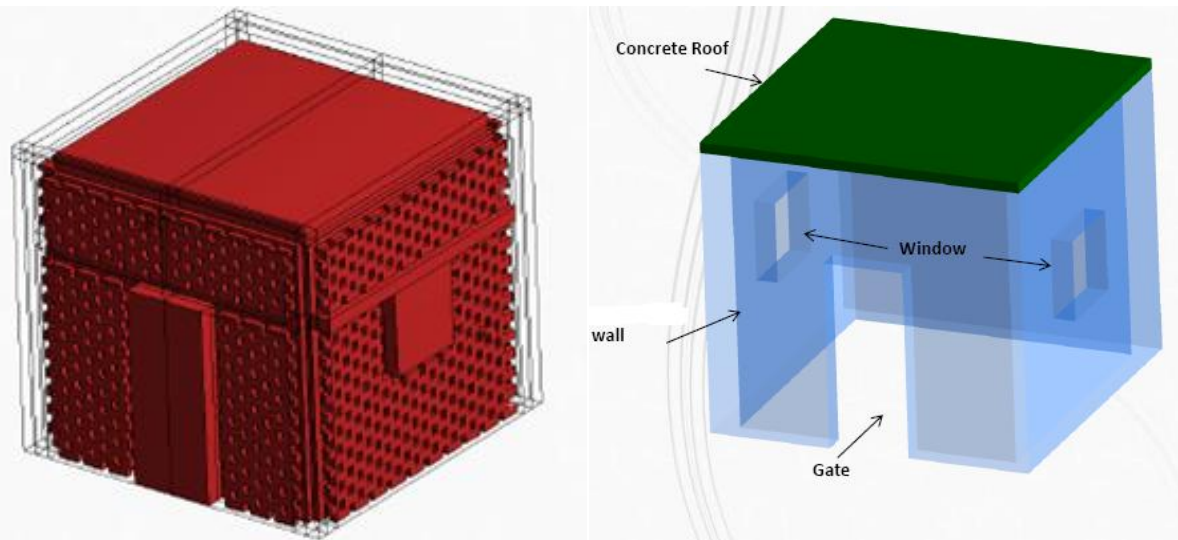

Figure 1. CAD generated model houses with rat trap bonded brick wall and mud block wall

\subsection{Boundary conditions applied for CFD analysis}

Climatic conditions normally existing in the southern parts of India were assigned for analysis on both types of model houses. The floor was assumed as adiabatic to simplify the computer analysis.

$>$ Inlet temperature of the incoming air is $30^{\circ} \mathrm{C}$ 
$>$ Incoming volume fraction of water vapor is $2.5 \%$ and remaining is air.

$>$ Velocity of the incoming air flow is $0.5 \mathrm{~m} / \mathrm{s}$

$>$ Ceiling Temperature is $40^{\circ} \mathrm{C}$

$>$ Side wall temperature is $30^{\circ} \mathrm{C}$

$>$ Floor wall is assumed to be adiabatic

$>$ Standard temperature and pressure were assumed as operating conditions

All boundary conditions were same for both the model houses except the wall thickness and construction method.

\subsection{Assumptions for CFD analysis}

$>$ The flow is assumed to be steady.

There is no external source to add and remove humidity within the room.

$>$ Density changes due to compressibility are neglected and as per ideal gas law density changes with respect to temperature is accounted.

$>$ The thermo physical properties except density of the fluid are assumed as constant.

$>$ Solar radiation is included by assuming fixed $40^{\circ} \mathrm{C}$ temperature at the ceiling

\subsection{Tools Used for CFD analysis}

$>$ Pre Processing - ANSYS Design Modeler and ANSYS Meshing

$>$ CFD Solver- ANSYS FLUENT 14.5 \& 15.0

\subsection{Material properties assigned for CFD analysis}

Material properties assigned for CFD analysis on the model houses were as presented in the table1.

\begin{tabular}{|l|l|l|l|l|l|}
\hline Materials & $\begin{array}{l}\text { Wall Thickness } \\
(\mathbf{m m})\end{array}$ & $\begin{array}{l}\text { Roof Thickness } \\
(\mathbf{m m})\end{array}$ & $\begin{array}{l}\text { Specific Heat Capacity } \\
(\mathbf{C p}) \mathbf{K J} / \mathbf{K g} . \mathbf{K}\end{array}$ & $\begin{array}{l}\text { Thermal } \\
\text { Conductivity (C) } \\
\text { W/M.K }\end{array}$ & $\begin{array}{l}\text { Density ( } \square) \\
\text { Kg/m3 }\end{array}$ \\
\hline $\begin{array}{l}\text { Rat Trap bond } \\
\text { Brick wall }\end{array}$ & 230 & 120 & 0.84 & 0.6 & 1820 \\
\hline Mud Block Wall & 250 & 120 & 0.92 & 2.5 & 2300 \\
\hline Concrete (Roof) & - & 150 & 0.90 & 1.13 & 2000 \\
\hline
\end{tabular}

Table 1. Material properties assigned for CFD analysis

\section{Results And Discussion}

Objective of the analysis was to observe the indoor relative humidity variations due to the outdoor air flow into the houses and heat gain by walls and roof from solar radiation and conduction into the inner space of the houses built with different wall materials. The relative humidity contours obtained during CFD analysis were presented for both types of houses and compared.

\subsection{Relative Humidity contours across the flow at various XY Plane}

Figures $2 \mathrm{a}$ and $2 \mathrm{~b}$ show the contours of relative humidity variations in rat trap bond brick walled and mud block walled model houses for the same boundary conditions along XY direction.

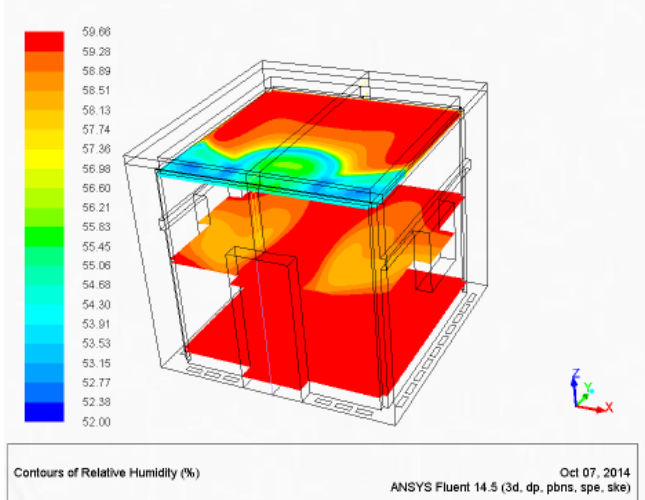

Figure 2 a. Rat trap bond brick wall contour

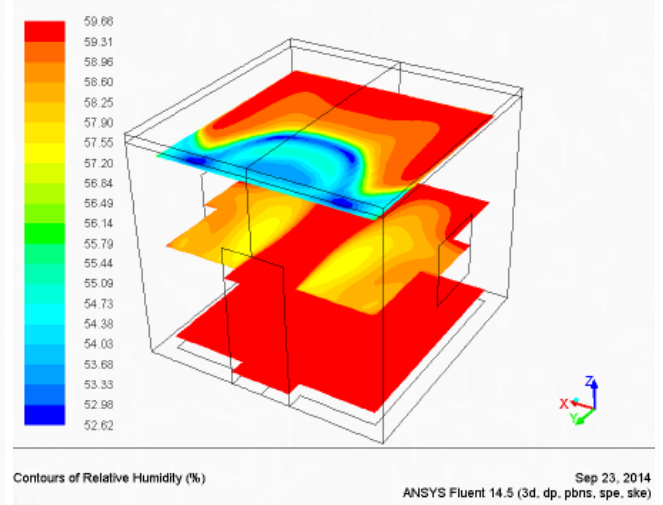

Figure 2 b. Mud block wall contour 
Due to direct solar radiation incident on the roof the roof temperature increases and the heat transfer into the inner space of the house takes place due to conduction. Also the solar heat gain by the walls will be conducted into the house. As there are no humidity generating sources inside the house the difference in relative humidity value compared with outdoor conditions will be very less. But due to air flow into the house through front door opening and because of the heated roof the relative humidity variations will be considerable near the roof adjacent to the door. The drop in relative humidity value will be more in mud block walled house than rat trap bond brick walled house. It was due to the more heat gain by the mud block wall compared with rat trap bond brick wall. In rat trap bond wall the air space within the wall construction will prevent more heat transfer from surroundings into the inner space. The difference can be clearly viewed in the upper XY plane near roof. Also due to air inlet through two side windows some variation in relative humidity will occur in both houses. The same can be observed in the middle XY plane near window openings on both sides. The variation was higher in the case of mud block walled house. In the bottom XY plane adjacent to the floor no relative humidity variation was observed as the floor was assumed to be adiabatic.

\subsection{Relative Humidity contours along the flow at various YZ Plane}

Figures $3 \mathrm{a}$ and $3 \mathrm{~b}$ show the contours of relative humidity variations in rat trap bond brick walled and mud block walled model houses for the same boundary conditions along YZ direction.

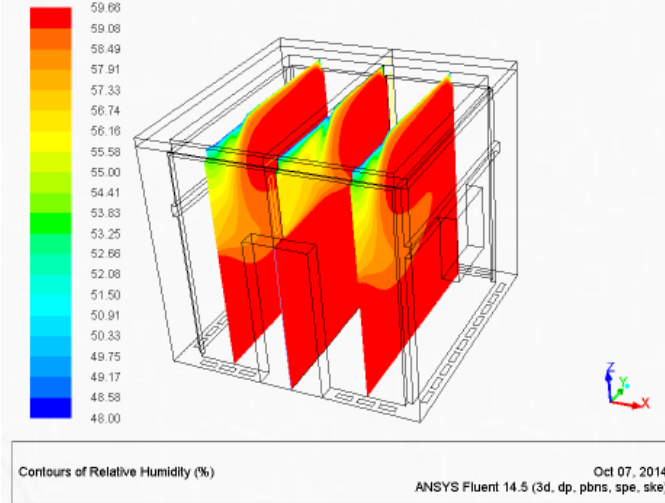

Figure 3 a. Rat trap bond brick wall contour

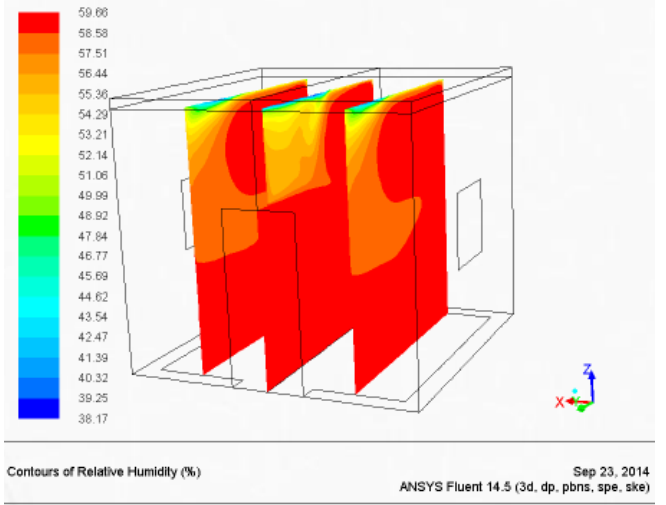

Figure 3 b. Mud block wall contour

As the temperature variations occur mostly along $\mathrm{Z}$ directions three $\mathrm{YZ}$ planes one in the middle and other two adjacent to the side walls were considered for analysis. More variations in the relative humidity near front door adjacent to the roof and less variation near window openings in the side walls were observed. No change in the relative humidity value in other inner spaces when we go deeper was also noticed as represented in figures $3 \mathrm{a}$ and $3 \mathrm{~b}$. Relative humidity values reduction was more in mud block walled house than the rat trap bond brick walled house.

\subsection{Relative Humidity contours within air domain at various XZ Plane}

Figures $4 \mathrm{a}$ and $4 \mathrm{~b}$ show the contours of relative humidity variations in rat trap bond brick walled and mud block walled model houses for the same boundary conditions along XZ direction.

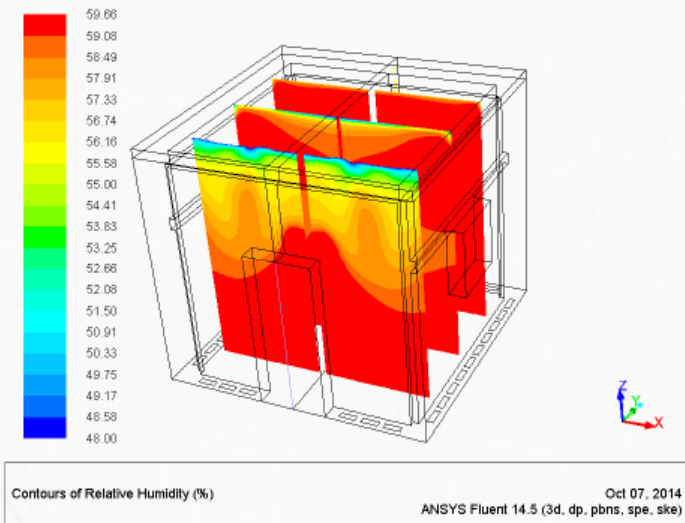

Figure 4 a. Rat trap bond brick wall contour

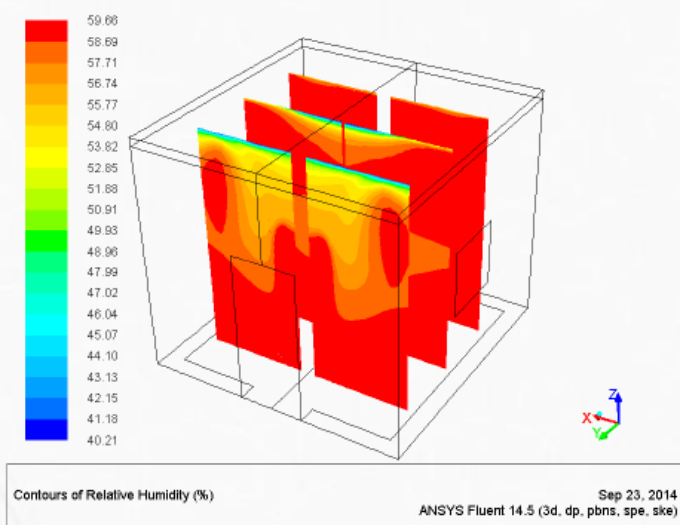

Figure 4 b. Mud block wall contour 
Three planes along XZ direction one plane near front door, second plane in the middle and the other plane adjacent to the back wall were considered for analysis. The effect of air entry through the door was clearly understood from the first plane. Also the relative humidity variation when we go towards the floor was clearly visible in the figures $4 \mathrm{a}$ and $4 \mathrm{~b}$. No relative humidity variation was noticed in the inner space adjacent to the back side wall and floor. Slightly more increase in relative humidity observed in the case of mud block walled house.

\subsection{Relative Humidity contours within air domain at various mid planes}

Figures $5 \mathrm{a}$ and $5 \mathrm{~b}$ show the contours of relative humidity variations in rat trap bond brick walled and mud block walled model houses for the same boundary conditions along mid planes in $\mathrm{XY}, \mathrm{YZ}$ and $\mathrm{XZ}$ direction.

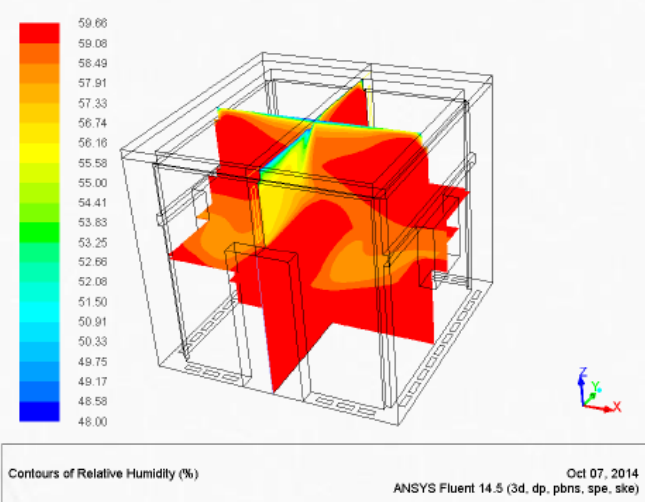

Figure 5 a. Rat trap bond brick wall contour

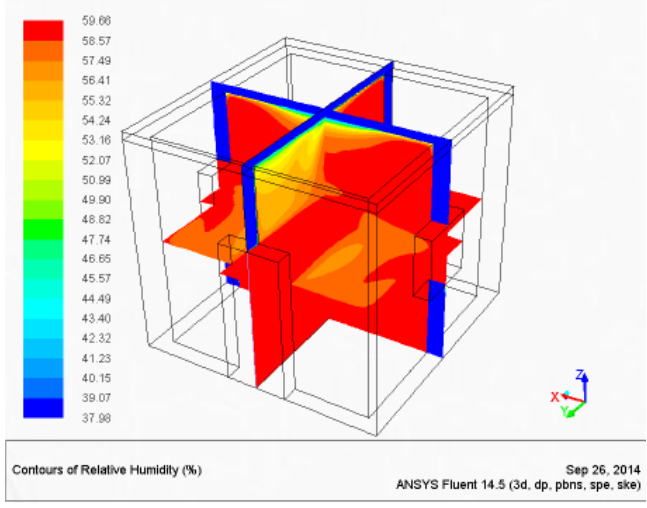

Figure 5 b. Mud block wall contour

To analyze the comparatively the relative humidity variations in all the directions the mid plane contours will assist. The outdoor air flow into the houses takes place along these planes. The heat intake and also the low relative humidity value of the air intake lower the relative humidity inside the houses. This effect was more near the front door adjacent to roof, where the amount of air entry and heat transfer was more. In the inner spaces the relative humidity variations are negligible and they may vary depending on the air flow provisions either natural or forced. Slightly lower values of relative humidity were observed in mud block walled house than the rat trap bond walled house near the openings.

\subsection{Overall observations made from CFD analysis}

$>$ Pattern of relative humidity distribution in both the mud block and rat trap bond brick walled houses were same.

$>$ The percentage of relative humidity is decreasing near the upper half of the rooms as air is absorbing some heat from the ceiling.

$>$ Effect of heated roof is negligible inside the lower half of the room because air is being introduced forcefully through the front door which cools the air inside the houses.

$>$ Velocity of the air near the window is increasing to accommodate the incoming flow rate.

\subsection{Measured relative humidity variations}

Outdoor relative humidity values measured in the region where the model houses were located range from $54 \%$ to $94 \%$, and the monthly average value of relative humidity range from $59 \%$ to $71 \%$. During hot day time the humidity was less and the value increases during night time. During winter and rainy days the outdoor humidity was very high.

Indoor relative humidity values were slightly higher than the outdoor values as there was no dehumidification and the humidity values mount up because of incoming fresh air. As fresh air with low humidity values enters the values were less near the door and windows. Spaces away from the openings were with high relative humidity. Up to $4 \%$ increase in case of rat trap boned brick walled house and up to $6 \%$ increase in case of mud block walled house were observed nearer to the simulation results.

\section{Conclusion}

Relative humidity variations inside the houses depend on the heat gain from roof and walls. The majority of heat transfer into the houses depends on the material properties of the building materials mostly the wall and roof. More the heat gain more the variations in relative humidity values. Also the rate and volume of 
outdoor air flow into the houses will alter relative humidity values. Controlling the door and window openings will result in the variations in relative humidity inside the houses. The wall materials having higher specific heat capacity and higher thermal conductivity will transfer more heat into the houses and hence to control the relative humidity in such cases either natural or mechanical ventilation provisions for fresh air inflow are required. Mud block houses posses more relative humidity fluctuations than rat trap bond brick walled houses. Hence rat trap bond brick wall construction method will provide comfortable humidity levels in rural houses with suitable ventilation arrangements. Similar simulation analysis with varying boundary conditions will assist a builder to choose suitable materials for residential buildings which provide comfort to the occupants.

\section{Acknowledgement}

The authors wish to acknowledge the Innovent Engineering Solutions Private Limited, Bangalore, India- 560038, (www.innoventengg.com), for their support in doing CFD simulation with CFD Solver - ANSYS Fluent 14.5, on the mud block walled and rattrap bond brick walled CAD model houses.

\section{References}

[1]. Gholamreza Heravi, Mahsa Qaemi, Energy performance of buildings: The evaluation of design and construction measures concerning building energy efficiency in Iran, Energy and Buildings 75 (2014)456-464

[2]. Wang Liping, Wong Nyuk Hien, The impacts of ventilation strategies and façade on indoor thermal environment for naturally ventilated residential buildings in Singapore, Building and Environment 42 (2007) 4006 - 4015

[3]. Oluwafemi K. Akandel and Micheal A. Adebamowo, Indoor thermal comfort for residential buildings in hot-dry climate of Nigeria, Proceedings of conference: Adapting to change: New thinking on comfort, 9-11 April 2010. Network for comfort and energy use in buildings, http://nceub.org.uk

[4]. Harimi Djamila, Chi-Ming Chu, Sivakumar Kumaresan, Effect of Humidity on tropical comfort in the humid tropics, Journal of building construction and planning research, 2014, 2, 109-117

[5]. ASHRAE Position document on Limiting indoor mold and dampness in buildings, 2012 ASHRAE

[6]. Zainazlan Md Zain, Mohd Nasir Taib, Shahrizam Mohd Shah Baki, Hot and humid climate: Prospect for thermal comfort in residential building, Desalination 209 (2007) 261-268

[7]. Florian Antretter Andreas Holm, DrIng, Achilles Karagiozis, Samuel Glass, Associate member ASHRAE, Interior temperature and relative humidity distributions in mixed humid and cold climates as building simulation boundary conditions.

[8]. Monika Woloszyn, Targo Kalamees, Marc Oliver Abadie, Marijke steeman, Angela Sasic Kalagasidis, The effect of combining a relative humidity sensitive ventilation sustem with the moisture buffering capacity of materials on indoor climate and energy efficiency of buildings, Building and Environment, 44 (2009) 515- 524

[9]. Anthony V, Arundel, Elia M, Sterling, Judith H.Biggin, Theodor D.Sterling, Indirect health effects of relative humidity in indoor environments, Environmental health prospective, Vol.65, pp.351-361, 1986

[10]. Steve Emmerich, Andrew Persily, Steven Nabinger, Modeling moisture in residential buildings with a multizone IAQ program

[11]. Byungseon Sean Kim, Sanghyum Park, Jongchan Lee, Taesup Lim, Indoor humidity influenced by the stack effect in high rise residential buildings, Proceedings; building Simulation 2007-886

[12]. Hartwig M. Kunzel, Indoor relative humidity in residential buildings- a necessary boundary condition to assess the moisture performance of building envelope systems.

[13]. Nour Lajimii, Noureddine Boukadidai, Thermal and moisture behavior of premise exposed to real climate condition, International Journal of Emerging Technologies in Computational and Applied Sciences, IJETCAS 14-508; 2014 